\title{
Usefulness of Salivary and Serum Auto-antibodies Against Tumor Biomarkers HER2 and MUC1 in Breast Cancer Screening
}

\author{
Fatna Laidi $^{1 *}$, Amal Bouziane ${ }^{2}$, Abdelhamid Errachid ${ }^{3}$, Fatima Zaoui ${ }^{1}$
}

\begin{abstract}
Background: The aim of this work was to investigate if serum and salivary auto-antibodies, isotypes IgG and IgM, against HER2 and MUC1 tandem repeat fragments could play a role in breast cancer screening. Materials and Methods: Our case-control study was conducted in breast cancer patients, in early stages $(n=29)$, at the gynecology service, Maternity Souissi Hospital, Rabat, Morocco and healthy woman $(n=31)$. Salivary and serum auto-antibodies against HER2 and MUC1 (tandem repeat) were assessed by enzyme-linked immunosorbent assay (ELISA) and compared between patients and healthy women using the Mann-Whitney U test. A P-value $<0.05$ was considered to be statistically significant. Results: Our data showed higher expression of all serum and salivary autoantibodies in patients as compared to healthy women $p<0.05$. However, serum IgM anti-MUC1 expression did not show a significant difference between cases and controls $(p=0.79)$. Similarly, salivary IgG anti-HER2 expression did not differ $(p=0.15$ ). The correlation between the different isotypes of antibodies revealed that the highest correlation was between salivary IgG anti-HER2 and salivary IgG anti- MUC1( $r=0.65)$. In fact, we have found in saliva the correlation between autoantibodies anti-MUC1 and anti-HER2 more important than in serum ( $r=0.59$ and $r=0.55$ ). However, the correlation between serum and saliva values for all antibodies was weak. Conclusions: Autoantibodies against HER2 and MUC1 may provide a useful approach in breast cancer screening when using both serum and saliva values.
\end{abstract}

Keywords: Breast cancer - autoantibodies - HER2 - MUC1 - saliva - serum

Asian Pac J Cancer Prev, 17 (1), 335-339

\section{Introduction}

Breast cancer is the most common cancer and considered as the second cause of mortality in woman (Begum et al., 2012). Early detection of this pathology is very useful way to decrease it (Tjemslanda and Soreide, 2004). Currently, mammography stills the gold standard test for breast cancer screening (Tarhan et al., 2014). However, breast cancer may be hard to detect in some women with dense breast tissues (Tarhan et al., 2013; Tarhan et al., 2014). Consequently, circulating tumors biomarkers attracted more attention to detect cancer at an early stage, in diagnosis, treatment and metastasis prediction (Porika et al., 2010; Maric et al., 2011). In breast cancer, many biomarkers are used for this purpose such as HER2 (human epidermal growth factor receptor) and CA 15-3 (Cancer Antigen) (Maric et al., 2011; Moazzezy et al., 2014). In fact, HER2 is overexpressed in 20\%-25\% of breast cancers, gene amplification has been observed in
$30 \%$ of metastatic breast cancers and it is associated with a poor prognosis and resistance to certain chemotherapeutic agents (Slamon et al., 1987; Muss et al., 1994; Tsé (2010). Thus, invasive breast cancer with positive HER2 status is targeted by Trastuzumab (a recombinant humanized monoclonal antibody directed against the extracellular domain of HER2) and lapatinib inhibits tyrosine kinase activity of receptors HER1 and HER2 (Sotelo et al., 2014). As regards CA 15-3, high levels of this protein is correlated to tumor size, and it could predict a bone and liver metastases in 60-80\% of breast cancer cases (Maric et al., 2011; Atoum et al., 2012; Zhang et al., 2013). CA $15-3$ is used to assess overexpression of MUC1 gene. This gene encode a transmembrane mucin (MUC1 called also PEM) overexpressed in over $90 \%$ of breast tumors (Kufe (2013). MUC1 is a transmembrane protein with an extracellular domain consisting of a variable number of 20-amino acid tandem repeats (VNTR) rich in Serine, Threonine and Proline (Gendler et al., 1988). Otherwise,

${ }^{1}$ Oral Biomechanics and Biotechnology Research Unit, Faculty of Dental Medicine, ${ }^{2}$ Department of Periodontology, Faculty of Dental Medicine, Biostatistical, Clinical and Epidemiological Research Laboratory, Faculty of Medicine and Pharmacy, University Mohammed V, Rabat, Morocco, ${ }^{3}$ Institute of Analytical Sciences (ISA), University of Lyon, Villeurbanne, France * For correspondence: laidi.fatna@gmail.com 
Fatna Laidi et al

MUC1 reveals an immunodominant peptide along its tandem repeat (TR) that has been used as a target to tumor immunotherapy (Pinkhasov et al., 2011). Similarly, many data showed that the immune system often reacts against tumor cells earlier (Desmetz et al., 2011). In fact, changes in protein regulation in tumorigenesis process may generate an immune response (Murphy et al., 2012). Thus, autoantibodies produced against tumor biomarkers may provide a useful approach in cancer screening (Chapman et al., 2007). The detection of antibodies may be more useful than tumor biomarkers. In fact, humoral response is amplified even in small quantity of antigen. This may reflect the high concentration of antibodies in blood (Murphy et al., 2012). Moreover, Autoantibodies endure months and years in patient's circulation and could be detected even in long period. Antibodies are relatively stable because it does not undergo proteolytic cleavage (Murphy et al., 2012). Autoantibodies are accessible in serum or plasma and it may avoid the need to invasive procedures (Murphy et al., 2012). Moreover, autoantibodies could be assessed also in saliva which could provide noninvasive solution for breast cancer screening (Arif et al., 2014). We have shown in previous studies the limits of using proteins HER2 and CA 15-3 in breast cancer detection (Laidi et al., 2014; Laidi et al., 2014) and the aim of this work is to investigate if serum and salivary auto-antibodies, isotypes $\operatorname{IgG}$ and $\operatorname{IgM}$, against HER2 and MUC1 tandem repeat fragment could play a role in breast cancer screening.

\section{Materials and Methods}

\section{Patients}

Our case-control study was conducted in breast cancer patients $(n=29)$, in early stages, no visible metastatic disease, at the gynecology service, Maternity Souissi Hospital, Rabat, Morocco at the age of 47.24 \pm 9.52 and healthy women $(n=31)$ aged $43.45 \pm 14.72$. This study was conducted after obtaining the approval of local ethic committee for biomedical research and each participant signed a consent form and answered a brief questionnaire before the test.

\section{Saliva and serum collection}

Sampling of saliva and blood was realized in the morning and each participant rinsed her mouth several times and asked not to eat, drink, or smoke for at least 2 hours before the test.

The collection protocol of samples is mentioned with details in previous works (Laidi et al., 2014; Laidi et al., 2014). In brief, we collected $5 \mathrm{ml}$ of stimulated saliva by chewing gum and blood samples were collected in serum tubes. The saliva and blood were centrifuged at 2,000 rpm for 10 minutes. Then saliva supernatant and serum were stored at $-80^{\circ} \mathrm{C}$.

Assessment of auto-antibodies against HER2 and MUC1, tandem repeat fragment by ELISA

ELISA plates were coated with $100 \mu 1$ of recombinant

Table 1. OD of Salivary and Serum Auto-antibodies against HER2 and MUC1 Tandem Repeat Fragment

\begin{tabular}{llcc}
\hline OD of Auto-antibodies & $\begin{array}{c}\text { Breast cancer patients } \\
\mathrm{n}=29\end{array}$ & $\begin{array}{c}\text { Healthy volunteers } \\
\mathrm{n}=31\end{array}$ & $\mathrm{p}$ value \\
\hline Serum expression of auto-antibodies & & & $<0.001$ \\
$\quad$ serum IgG anti-MUC1 & $1.28 \pm 0.3$ & $0.68 \pm 0.17$ & 0.79 \\
$\quad$ serum IgM anti-MUC1 & $0.67 \pm 0.22$ & $1.02 \pm 0.16$ & $<0.001$ \\
$\quad$ serum IgG anti-HER2 & $1.74 \pm 0.76$ & $0.98 \pm 0.15$ & 0.003 \\
$\quad$ serum IgM anti-HER2 & $1.21 \pm 0.35$ & $0.25(0.24 ; 0.3)$ & $<0.001$ \\
Salivary expression of auto-antibodies & $0.68(0.39 ; 0.97)$ & $0.94(0.06 ; 0.13)$ & 0.02 \\
$\quad$ salivary IgG anti-MUC1 & $0.06(0.05 ; 0.08)$ & $0.21(0.16 ; 0.46)$ & 0.15 \\
$\quad$ salivary IgM anti-MUC1 & $0.3(0.15 ; 0.78)$ & $0.1(0.07 ; 0.26)$ & 0.007 \\
$\quad$ salivary IgG anti-HER2 & $0.2(0.11 ; 0.47)$ & & \\
$\quad$ salivary IgM anti-HER2 & & & \\
\hline
\end{tabular}

OD: optical density

Table 2. OD of Salivary and Serum Auto-antibodies against HER2 and CA 15-3 According to HER2 Status

\begin{tabular}{lcc}
\hline OD of Auto-antibodies & $\begin{array}{c}\text { Breast cancer patients } \\
\text { with positive HER2 status } \\
n=10\end{array}$ & $\begin{array}{c}\text { Breast cancer patients } \\
\text { with negative HER2 status } \\
n=12\end{array}$ \\
\hline Serum expression of auto-antibodies & & $\begin{array}{c}\mathrm{p} \text { value } \\
\text { serum IgG anti-MUC1 }\end{array}$ \\
serum IgM anti-MUC1 & $1.30 \pm 0.30$ & $0.58 \pm 0.28$ \\
serum IgG anti-HER2 & $0.75 \pm 0.15$ & $1.83 \pm 0.73$ \\
serum IgM anti-HER2 & $1.74 \pm 0.9$ & $1.15 \pm 0.44$ \\
Salivary expression of auto-antibodies & $1.36 \pm 0.2$ & 0.79 \\
salivary IgG anti-MUC1 & & $0.44(0.38 ; 0.75)$ \\
salivary IgM anti-MUC1 & $0.78(0.61 ; 1)$ & $0.06(0.05 ; 0.18)$ \\
salivary IgG anti-HER2 & $0.06(0.05 ; 0.07)$ & $0.3(0.12 ; 0.73)$ \\
salivary IgM anti-HER2 & $0.58(0.14 ; 0.89)$ & $0.21(0.1 ; 0.5)$ \\
\hline
\end{tabular}

OD: optical density 
Table 3. Correlation between Different Isotypes of Salivary And Serum Auto-Antibodies

\begin{tabular}{|c|c|c|c|}
\hline \multicolumn{2}{|c|}{ Isotypes of antibodies } & $\mathrm{r}$ (coefficient of correlation) & $P$ value \\
\hline Serum IgM anti-HER2 & serum IgM anti-MUC1 & 0.59 & $<0.001$ \\
\hline Salivary IgM anti-HER2 & salivary IgM anti- MUC1 & 0.31 & 0.01 \\
\hline Serum IgG anti-HER2 & serum IgG anti- MUC1 & 0.55 & $<0.001$ \\
\hline Salivary IgG anti-HER2 & salivary IgG anti- MUC1 & 0.65 & $<0.001$ \\
\hline Salivary IgG anti- MUC1 & serum IgG anti- MUC1 & 0.38 & 0.003 \\
\hline Salivary IgM anti-MUC1 & serum IgM anti-MUC1 & 0.04 & 0.74 \\
\hline Salivary IgM anti-HER2 & serum IgM anti-HER2 & 0.16 & 0.20 \\
\hline Salivary IgG anti-HER2 & serum IgG anti-HER2 & 0.24 & 0.06 \\
\hline
\end{tabular}

proteins HER2 (RayBiotech; Norcross, GA; USA) and MUC1, tandem repeat fragment (Abgent; San Diego, CA; USA) in each well. Recombinant proteins were diluted in bicarbonates buffer $(0.05 \mathrm{M}, \mathrm{pH}=9.5)$ to $2 \mu \mathrm{g} / \mathrm{ml}$. ELISA plates were incubated at $4{ }^{\circ} \mathrm{C}$ overnight. After incubation, rest of recombinant protein solution was removed and we added $100 \mu 1$ of PBS Blocking Buffer 5\% BSA to each well. Then, incubation of plates $2 \mathrm{~h}$ at $37^{\circ} \mathrm{C}$. The plates were washed, 5 times by PBS-tween $20(0.05 \%) .100 \mu 1$ of Standards and samples (saliva and sera) were added to appropriate wells. The standards used in each test were positive and negative serum at different dilutions $(1 / 50$, $1 / 100,1 / 200,1 / 400,1 / 800,1 / 1600,1 / 3200)$ serum samples were diluted $1 / 100$ and saliva were diluted $1 / 5$. After incubation of plates $1 \mathrm{~h}$ at room temperature and washing 5 times, $100 \mu 1$ of HRP-conjugated antibodies anti-human IgM and IgG (SouthernBiotech; Birmingham, USA) were added to wells diluted respectively $1 / 4000$ and 1/10000. TMB substrate solution was used to reveal the complex antigen-antibody bound. We incubated 30min and the reaction was stopped and absorbance was read at $450 \mathrm{~nm}$.

\section{Statistical analysis}

The Mann-Whitney test was used to compare salivary expression of auto-antibodies and the data was expressed in median and interquartiles. The Student test was used to compare serum expression of auto-antibodies and data was expressed in mean and standard deviation. A p $<0.05$ was consider to be statistically significant.

\section{Results}

Our data has shown higher expression of all serum and salivary autoantibodies in patients comparing to healthy women $\mathrm{p}<0.05$. However, serum IgM anti-MUC1 expression did not show a significant difference between cases and controls $(\mathrm{p}=0.79)$. The same data was registered in salivary IgG anti-HER2 expression which was not also significant $(\mathrm{p}=0.15)$ (Table 1$)$.

We have also compared the expression of salivary and serum autoantibodies in patients according to the status of receptor HER2 in mammary tissues from medical records. The difference between patients with positive and negative HER2 status was not significant ( $\mathrm{p}>0.05)$ (Table 2).

Correlation between different isotypes of autoantibodies was assessed and we have found positive correlation between different isotypes of antibodies as shown in Table 3:

The most important correlations were registered
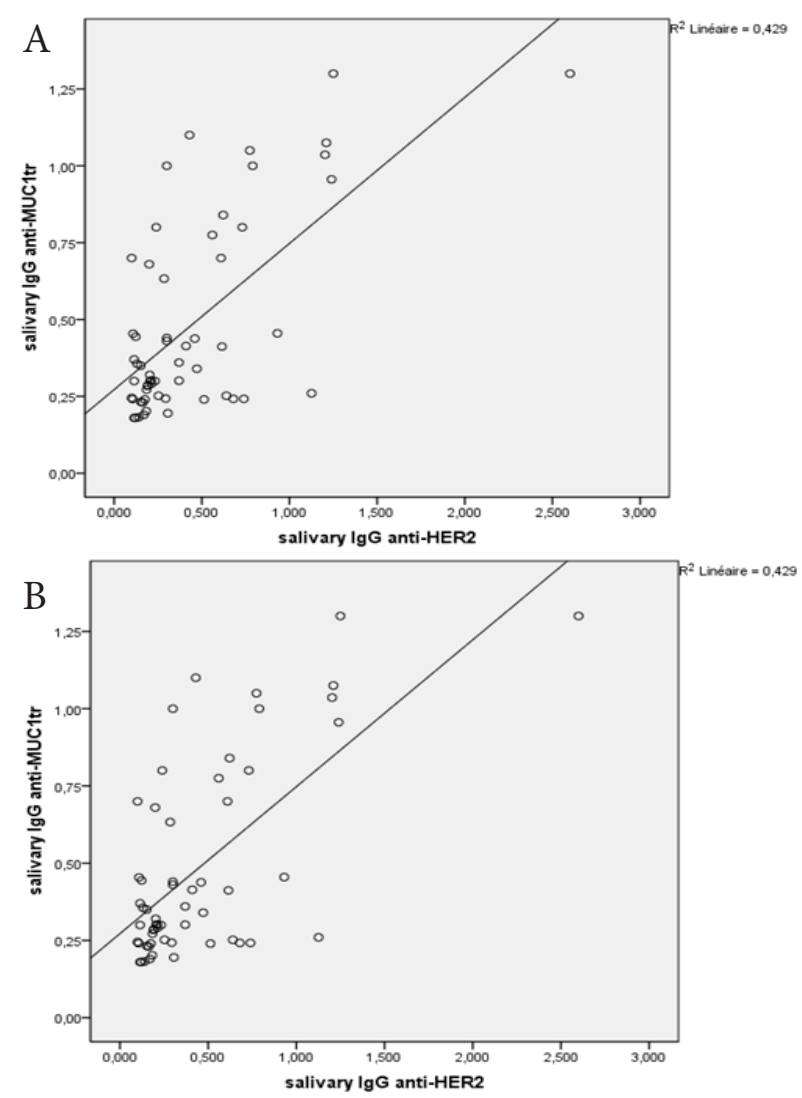

Figure 1. A) Correlation curve of salivary IgG antiHER2 and salivary IgG anti- MUC1 $(r=0.655)$, B) Correlation curve of serum IgM anti-HER2 and serum IgM anti-MUC1 (r=0.591)

between salivary IgG anti-HER2 and salivary IgG antiMUC1 (Fig A) and serum IgM anti-HER2 and serum IgM anti-MUC1 (Fig B).

\section{Discussion}

The aim of our research is to investigate the usefulness of auto-antibodies against tumor biomarkers HER2 and MUC1 in breast cancer screening in saliva and serum to provide a simple detection. Our data has shown that those autoantibodies may play a role in breast cancer screening. In fact, different isotypes of immunoglobulins ( $\mathrm{IgG}$ and IgM) against tumor biomarkers HER2 and MUC1 in both serum and saliva were significantly higher in patients with breast cancer comparing to healthy women. However, serum IgM anti-MUC1 and salivary IgG anti-HER2 were not elevated in patients comparing the control 


\section{Fatna Laidi et al}

group. Our data is supported by previous studies. Many researchers had an interest in auto-antibodies against tumor biomarkers such as HER2 and MUC1. All these studies had suggested the role that may play autoantibodies in breast cancer screening. In fact, case-control studies between breast cancer patients and healthy volunteers have shown a significant difference between serum or plasma expression of antibodies in patients and healthy women (Chapman et al., 2007; Tang et al., 2010; Lu et al., 2012; Isla et al., 2013; Evans et al., 2014).

Otherwise, the expression of serum or plasma antibodies anti-HER2 and MUC1, was found to be help in early detection of other cancers such as lung cancer, myeloma and colorectal cancer (Treon et al., 2000; Chapman et al., 2008; Wang et al., 2012). In all these studies the serum expression of antibodies was higher in patients except in patients with multiple myeloma which was higher in healthy donors (Treon et al., 2000; Chapman et al., 2008; Wang et al., 2012).

We have also analyzed the expression of autoantibodies according to the status of the receptor HER2 in mammary tissues from medical records. Our data did not reveal any significance. In fact, in patients with positive and negative HER2 status the expression of all autoantibodies was not significantly higher in patients or control group $(\mathrm{p}>0.05)$ except serum expression of IgM anti-HER2 which was elevated in patients with positive HER2 status ( $\mathrm{p}=0.007$ ).

As regards auto-antibodies expression in saliva, whole saliva contains a mixture of secretions from the salivary gland along with other constituents from the gingival crevicular fluid which is essentially serum exudate (Lamster and Ahlo, 2007; Al Kawas et al., 2012). Our data has shown that both isotypes IgG or IgM against HER2 or MUC1 (TR) were significantly higher in patients with breast cancer comparing of healthy women. The only marker that was not significantly higher in both patients and healthy donors was salivary IgG anti-HER2 $(\mathrm{p}=0.15$ $>0.05)$. The role that may play saliva in cancer diagnosis is known since the nineties (Humphrey and Williamson, 2001). In cancer detection many studies have suggested the usefulness of saliva in detecting autoantibodies of various types of cancer (Warnakulasuriya et al., 2000; Arif et al., 2014).

We have also analyzed the correlation between the different isotypes of antibodies to evaluate the possibility to use both immunoglobulin anti-MUC1 and anti-HER2 in breast cancer screening. Our data revealed that the highest correlation was between salivary IgG anti-HER2 and salivary IgG anti- MUC1(r=0.65). In fact, we have found in saliva the correlation between autoantibodies anti-MUC1 and anti-HER2 more important than in serum which was moderate $(r=0.59$ and $r=0.55)$. However, the correlation between serum and saliva of all others antibodies was weak.

In conclusion autoantibodies against HER2 and MUC1 may provide a useful approach in breast cancer screening. Additionally, saliva detection of antibodies of both anti-MUC1 and anti-HER2 in association may be more interesting than serum according to our data.

\section{References}

Al Kawas S, Rahim ZH, Ferguson DB (2012). Potential uses of human salivary protein and peptide analysis in the diagnosis of disease. Arch Oral Biol, 57, 1-9.

Arif S, Qudsia S, Urooj S, et al (2014). Blueprint of quartz crystal microbalance biosensor for early detection of breast cancer through salivaryautoantibodies against ATP6AP1. Biosens Bioelectron, 65, 62-70.

Atoum M, Nimer N, Abdeldayem S, et al (2012). Relationships among serum CA15-3 tumor marker, tnm staging, and estrogen and progesterone receptor expression in benign and malignant breast lesions. Asian Pac J Cancer Prev, 13, 857-60.

Begum M, Karim S, Malik A, et al (2012). CA 15-3 (mucin-1) and physiological characteristics of breast cancer from Lahore, Pakistan. Asian Pac J Cancer Prev, 13, 5257-1.

Chapman C, Murray A, Chakrabarti J, et al (2007). Autoantibodies in breast cancer: their use as an aid to early diagnosis. Ann Oncol, 18, 868-3.

Chapman CJ, Murray A, McElveen JE, et al (2008). Autoantibodies in lung cancer: possibilities for early detection and subsequent cure. Thorax, 63, 228-33.

Desmetz C, Lacombe J, Mange A, et al (2011). Autoanticorps et diagnostic précoce des cancers. Med Sci, 27, 633-8.

Evans RL, Pottala JV, Egland KA (2014). Classifying patients for breast cancer by detection of autoantibodies against a panel of conformation-carrying antigens. Cancer Prev Res, 7, 545-5.

Gendler S, Taylor-Papadimitriou J, Duhig T, et al (1988). A highly immunogenic region of a human polymorphic epithelial mucin expressed by carcinomas is made up of tandem repeats. J Biol Chem, 263, 12820-3.

Humphrey SP, Williamson RT (2001). A review of saliva: normal composition, flow, and function. J Prosthet Dent, 85, 162-9.

Isla Larrain MT, Colussi AG, Demichelis SO, et al (2013). Humoral immune response against tumoral mucin 1 (MUC1) in breast cancer patients. Int J Biol Markers, 28, 318-5.

Kufe DW (2013). MUC1-C Oncoprotein as a Target in Breast Cancer; Activation of Signaling Pathways and Therapeutic Approaches. Oncogene, 32, 1073-1.

Laidi F, Bouziane A, Lakhdar A, et al (2014). Salivary expression of soluble HER2 in breast cancer patients with positive and negative HER2 status. Onco Targets Ther, 7, 1285-9.

Laidi F, Bouziane A, Lakhdar A, et al (2014). Significant correlation between salivary and serum $\mathrm{Ca}$ 15-3 in healthy women and breast cancer patients. Asian Pac J Cancer Prev, 15, 4659-2.

Lamster IB, Ahlo JK (2007). Analysis of gingival crevicular fluid as applied to the diagnosis of oral and systemic diseases. Ann N Y Acad Sci, 1098, 216-9.

Lu H, Ladd J, Feng Z, et al (2012). Evaluation of known oncoantibodies, HER2, p53, and cyclin B1, in prediagnostic breast cancer sera. Cancer Prev Res, 5, 1036-3.

Maric P, Ozretic P, Levanat S, et al (2011). Tumor markers in breast cancer-evaluation of their clinical usefulness. Coll Antropol, 35, 241-7.

Moazzezy N, Farahany T-Z, Oloomi M, et al (2014). Relationship between preoperative serum CA15-3 and CEA levels and clinicopathological parameters in breast cancer. Asian Pac J Cancer Prev, 15, 1685-8.

Murphy MA, O'Leary JJ, Cahill DJ (2012). Assessment of the humoral immune response to cancer. J Proteomics, $\mathbf{7 5}$, 4573-9.

Muss HB, Thor AD, Berry DA, et al (1994). c-erbB-2 expression and response to adjuvant therapy in women with nodepositive early breast cancer. $N$ Engl J Med, 330, 1260-6. 
Pinkhasov J, Alvarez ML, Rigano MM, et al (2011). Recombinant plant-expressed tumour-associated MUC1 peptide is immunogenic and capable of breaking tolerance in MUC1. Tg mice. Plant Biotechnol J, 9, 991-1.

Porika M, Malotu N, Veldandi U-K, et al (2010). Evaluation of tumor markers in Southern Indian breast cancer patients. Asian Pac J Cancer Prev, 11, 157-9.

Slamon DJ, Clark GM, Wong SG, et al (1987). Human breast cancer: correlation of relapse and survival with amplification of the HER-2/neuoncogene. Science, 235, 177-2.

Sotelo MJ, García-Sáenz JA, Manso L, et al (2014). Lapatinib plus trastuzumab in pretreated human epidermal growth factor receptor 2-positive metastatic breast cancer. J Cancer Res Ther, 10, 967-2.

Tang Y, Wang L, Zhang P, et al (2010). Detection of circulating anti-mucin 1 (MUC1) antibodies in breast tumor patients by indirect enzyme-linked immunosorbent assay using a recombinant MUC1 protein containing six tandem repeats and expressed in Escherichia coli. Clin Vaccine Immunol, 17, 1903-8.

Tarhan M-O, Gonel A, Kucukzeybek Y, et al (2013). Prognostic significance of circulating tumor cells and serum ca15-3 levels in metastatic breast cancer, single center experience, preliminary results. Asian Pac J Cancer Prev, 14, 1725-9.

Tarhan Geeraert N, Klausz R, Cockmartin L, et al (2014). Comparison of volumetric breast density estimations from mammography and thorax CT. Phys Med Biol, 59, 4391-9.

Tjemslanda L and Soreide JA (2004). Operable breast cancer patients with diagnostic delay oncological and emotional characteristics. Eur J Surg Oncol, 30, 721-7.

Treon SP, Maimonis P, Bua D, et al (2000). Elevated soluble MUC1 levels and decreased anti-MUC1 antibody levels in patients with multiple myeloma. Blood, 96, 3147-3.

Tsé C (2010). sHER-2: a novel marker? Med Nucl, 34, 66-1.

Wang YQ,Zhang HH, Liu CL, et al (2012). Correlation between auto-antibodies to survivin and MUC1 variable number tandem repeats in colorectal cancer. Asian Pac J Cancer Prev, 13, 5557-2.

Warnakulasuriya S, Soussi T, Maher R, et al (2000). Expression of p53 in oral squamous cell carcinoma is associated with the presence of IgG and IgA p53 autoantibodies in sera and saliva of the patients. J Pathol, 192, 52-7.

Zhang S-J, Hu Y, Qian H-L, et al (2013). Expression and significance of ER, PR, VEGF, CA15-3, CA125 and CEA in judging the prognosis of breast cancer. Asian Pac J Cancer Prev, 14, 3937-40. 